\title{
Data protection and the clinician: guidelines on data security
}

\author{
JOHN D WILLIAMSON
}

One of the byproducts of the 1984 Data Protection Act is that health authorities have been reviewing their policies and codes of practice on confidentiality and associated issues. Many have been startled at the gaping holes that have appeared in their policies as a result of the new legislation. Stimulated by the Department of Health and Social Security, most authorities are now reviewing their arrangements not only for computerised but also for manually held records.

Clinical practice depends on the patient trusting the doctor. That in turn depends on the degree of faith that the patient has in the doctor's ability or willingness to maintain the secrecy of confidential information freely given. The patient knows that any information so volunteered will be seen and possibly used by many different health professionals, but he gives the required information anyway because he has faith in the intentions of the staff concerned and in the doctor's authority in the control of information spread.

There is a snag. Benjamin Franklin rather cynically said that "three may keep a secret if two of them are dead." It is hard to maintain a confidence when it has to be passed between people who have no interest in whether it is known or not. Carelessness breeds inadvertent publicity. Dull routine may prompt excessive interest in the private lives of others and damaging anecdotes may enliven a boring job.

Leaks and other unauthorised disclosures of private information are common in commerce and industry for the relations between those enterprises and their employees are markedly different from that between a health service and its staff. The latter are believed to be motivated by more than a need to earn a wage or salary and this protects the institution and its patients from abuse. Yet the health service does suffer from breaches of confidence.

\section{Advent of the computer}

Before the computer arrived it was difficult for staff to obtain private information. Manual records, even if legible, take time to rifle through and are seldom stored in an order that would be of use to a would be snoop. Electronically stored records, however, are instantly available to the initiated in whatever order or format he chooses at the press of a button. Worse still, while the dedicated spy must go to a central record filing store to gain access to manual records, he can call electronic records to him provided that he can tap into the appropriate network. As any cinema goer or television watcher knows tapping in is child's play. All the potentia information seeker needs is some basic computer skill, a computer, and either a marked curiosity or criminal intent.

Computer crime is on the increase. This is not startling given the ease with which miscreants can gain access to private information and the amount of such information storable in any one system. Transfer of data is so simple with modern technology that many computer systems are designed to store more information than the user is likely to need and to transfer such data

Barnsley S75 2TR

JOHN D WILLIAMSON, MB, community physician and general practitioner Correspondence to: Athena, 24 Westville Road, Barnsley S75 2TR. quickly and efficiently to remote sites. Users have found it cheaper to use small computer installations themselves, drawing on private information in large data banks held by other organisations as required. Economy has led to the widespread practice of sharing data. This, too, helps the computer criminal who wants to enter the system. This might be considered irrelevant in the health service but it has data banks (remote and local), computer networks, and access points, though the National Health Service does not usually have data with obvious profit potential, except possibly for blackmail.

Most computer crime, however, is not committed for personal gain. No less than $85 \%$ of such crime is perpetrated by employees, mostly because of malice towards the organisation, the boss, or an immediate supervisor. The health service is clearly not invulnerable.

The development of computer technology resulted in the separation of the ideal of data security from that of confidentiality. Whereas data security relates to the way in which information is protected from unauthorised eyes, confidentiality concerns the way in which decisions about disclosure of information are made. Thus, confidentiality is concerned with who is allowed access to particular bits of data while data security is concerned with stopping anyone else joining in. In some respects it is an artificial distinction but it is none the less important, if only because of the implementation of the Data Protection Act. ${ }^{1}$

Parliament was concerned at the electronic revolution and was determined to do whatever it could to protect sensitive information about particular individuals. The $1984 \mathrm{Act}$ is the outcome, seeking to encourage good practice in data management, to set minimum standards of practice, and to enforce such standards through criminal law. In addition, the Act provides for access by the data subject to certain categories of information concerning himself. To achieve this eight principles of data protection have been developed

(1) Personal data shall be obtained and processed fairly and lawfully

(2) Personai data shall be held only for specified and lawful purposes.

(3) Personal data shall be disclosed only in pursuance of those specified and lawful purposes.

(4) Personal data shall be relevant, adequate, and not excessive.

(5) Personal data shall be accurate and up to date.

(6) Personal data shall not be held longer than necessary.

(7) Personal data shall be secured from unauthorised access or damage.

(8) Personal data shall be subject to the view, correction, or erasure of the person to whom they relate.

Apart from constituting an offence in itself, contravention of the principles may result in the data protection registrar issuing an order requiring the data user to take steps to stop breaches recurring. Failure to comply with such an order is itself an offence.

The new law does not concern itself much with the distinction between data security and confidentiality. All it is concerned about is the protection of the data, but, clearly, you cannot be entirely covered if your physical security-that is, access codes, locked rooms, or authorisation checks-is adequate but you do not care who is authorised to access the data in the first place. Confidentiality is pre-eminent, particularly in a sensitive field such as health.

The new law relates to all forms of electronic storage or processing that includes personal data-that is, information relating to an identifiable living person-though there are some exceptions. Generally any computer or word processor that stores and processes personal data other than for simple text preparation needs to comply. The law also covers home computers or personal computers where these are used to store or process personal data other than data relating to the data user or his immediate family. As it is not uncommon for interested clinicians to take information home to put on their computer they must register their system with the registrar. If it is not theirs but, say, their son's he must register his computer facility as a "data user who also carries out a computer bureau." Failure to register is a new offence. 
The Data Protection Act will undoubtedly help to discourage people from breaching the privacy of electronically held data. It will not, sadly, have so much impact on manual records, which are not protected by this or any other Act. Health records of whatever variety, though, need to be kept secure. Clinicians, therefore, have a dual obligation to their patients: they must abide by the new law on electronic files, and they must secure and protect information kept on manual systems. It makes sense to combine these in one task, and to check that their management of information conforms with the new Act regardless of whether or not it is electronically based, for the principles at stake are the same for both types of record.

\section{Data protection officers}

Most health authorities will appoint a data protection officer, whose prime job will be to ensure that electronic records are secure but whose remit would undoubtedly extend to manual records. They will be backed by a district data protection committee composed of major users. At hospital or practice level, however, someone will have to take on the responsibility of ensuring the confidentiality of data-that is, data custodians-and its security-that is, data or systems administrators - for each system. In a clinical setting the data custodian will probably be a clinician and the system administrator will probably also be a clinician.

The main tasks of the data custodian in promoting confidentiality are:

(1) To produce, maintain, and update a code of practice for his system which covers the routines by which authorised personnel can access personal data.

(2) To authorise any alteration to the machinery or routines comprising his system where these have any impact on data protection-for example, the use of different types of terminals that may link with other systems not previously included and the changing of the format of staff access codes.

(3) To authorise access to files, in part or whole, on one occasion or continuously.

(4) To monitor the use of the system, including how authorised personnel use the data to which they are allowed access.

(5) To negotiate the release of information into data banks for which other data custodians carry responsibility.

To support the data custodian the system administrator's main tasks are:

(1) To ensure that the data custodian's code of practice covers all aspects of data security including $(a)$ the physical security of source documents, computer hardware, and printout or other hard copy-for example, magnetic tape; $(b)$ access codes or passwords to the system, its software, and its various levels of data, and (c) security policing techniques such as "time out" and continuous user logging.

(2) To monitor the operation of the code of practice.

(3) To issue appropriate access codes or passwords reflecting the conditions of authorisation to those persons authorised by the data custodian to obtain access to any part of the system.

(4) To settle any disputes in the use of data.

(5) To ensure that the system is registered with the data protection registrar or the district data protection committee if exempt from registration under the Act.

(6) To ensure that the system operates within the Data Protection Act. Although not specifically his task, the system administrator should also ensure that there is a data custodian for his system.

Two things are clear. Firstly, the two tasks outlined above overlap quite considerably. The two officers must be able to work together comfortably and cooperatively. Secondly, it is apparent that the emphasis is on computer data. There is no reason, however, why the concepts concerned cannot spread to manual systems and, indeed, there is every reason to encourage them to do so.

Clinicians must be prepared to enter the arena of data protection by playing their full part as data protection officers. In fairness it hardly requires a great deal of effort apart from writing the code of practice and even that, as we shall now see, is a relatively simple task, especially for manual records.

\section{Guidelines for a code of practice}

\section{NAME OF THE SYSTEM}

This sounds a trifle unnecessary but it is astonishing how often people want to refer to particular files and have difficulty because they do not know how to describe them. Since many files relate to clinical information on patients it is important for everyone concerned to be able to identify the component parent files. The file should be named, but in such a way that its use is fairly obvious. Neonatal information system is better than NN12/4.
Subfiles within the system should be identified and named, thus enabling all the users to specify additional features of a subfile's code of practice rather than writing it all out again. A main file labelled "Barnsley case registers" can therefore have several subfiles including, for example "Mental handicap register," "Physically disabled register," "Solvent abuse register," "Incontinence register," and so on

It may help to represent the hierarchy diagrammatically so as to show the relation between subfiles and the main files.

\section{PURPOSE OF THE CODE}

Most codes are simply to prevent unauthorised access to the data system and to define criteria of authorisation, though some additional purposes may be defined for special cases. All purposes should be aimed at maintaining public confidence in the system's ability to protect sensitive data.

If the health authority concerned has a formal policy on confidentiality and data protection or both then the code must conform to that. Does it? If so does it say so explicitly? There should be no need to mention the guide to the Data Protection Act, ${ }^{2}$ the Steering Group on Health Services Information's code of practice, ${ }^{3}$ or Departmental guidance, ${ }^{4}$ though where the authority's policy is unwritten this might be advisable.

Does this section include a statement that all employees are obliged to maintain secrecy, with unauthorised disclosure being subject to disciplinary action, and are the disciplinary sanctions outlined briefly?

\section{DESCRIPTION OF THE SYSTEM}

If the system is computerised in any way, shape, or form both the machinery - that is, hardware-and the programs - that is, software-used should be specified. This will be needed by district officers charged with ensuring data protection on a district wide basis. It will also be useful to avoid duplicate purchases of widely applicable software and to plan for equipment replacement on a controlled basis.

Are any parts of the system utilising shared facilities? For example, colour line printers are usually shared by several separate systems while most visual display units operate several electronic systems. In such cases it is necessary to define which systems each shared piece of equipment belongs to so that the relevant systems administrator and data custodian may be fully aware of their obligations for ensuring its safety and security. It may also be useful in debiting the appropriate budget when the system is replaced.

Does the system allow other systems to use part of its hardware or software? If others are allowed to share the machinery or programmes these must be identified by name. This does not mean only taking source data from another party and storing or processing it for them, a circumstance in which the user may be acting as a computer bureau and so must obtain advice from his district data protection officer. I am referring to the position where other systems may be using your line printers, visual display units, etc. If the system is a particular person's responsibility then he must specify who else can use parts of it for their own ends; it is up to the district data protection committee to ensure that this is acceptable.

Special problems occur with systems that share data with other systems. These other systems will have to state how they are to use these data in their own code of practice, but your own code should specify the uses for which you have collected the data in question. There will need to be a good deal of collaboration with other users over these important questions.

Where data or software are shared some free exchange of information between systems - that is, interfacing -will be necessary. This may be partial or complete, one way or two way, temporary or permanent. Interfacing may be effected by batch processing of data held on magnetic tape, magnetic disc, punched cards, etc; intermittent-operated by opening a switch on the donor system to permit data disclosure or software sharing; or permanent 
-tied into a network of electronic installations. If either of the latter two is used there is less control of who can use the shared material; anyone with the appropriate passwords will be able to obtain access to the material regardless of which systems they operate, provided that their system also participates in the same network. If this applies to a system that you are responsible for produce a network diagram, enlisting the aid of your district data protection officer, so that the district data protection committee can satisfy itself on the security of its networks and computer interfaces.

\section{DESCRIBE ANY USE OF EXTERNAL SYSTEMS}

Are your data stored or processed outside the health service? This includes local authority, commercial, and personal computer systems but it may also relate to similarly disparate handling of manual records. If such facilities are used are they registered with the health authority and, if necessary, with the data protection registrar? If so, does the health authority have an agreement with the owners of the system(s) to maintain the confidentiality of health service data, and are there any contractual agreements that could result in civil action against breaches of confidentiality by such agencies?

Have people who store or process health service information but who are not National Health Service employees signed an agreement to maintain confidentiality personally? Have they signed a similar agreement to abide by the code of practice relating to the data that they are in contact with? What sanctions are there for breaches of such agreements?

\section{OWNERSHIP OF DATA}

In most, but not all, cases the Secretary of State for Social Services will "own" the data. Where ownership is in doubt the data custodian should seek professional advice through the district data protection officer. If ownership is deemed to belong elsewhere is the system operating as a data bureau? If so, there are additional registration requirements under the Data Protection Act. Even in this case the present guidelines are applicable since they form the basis for ensuring the protection of data held in any system.

\section{DESIGN OF THE SYSTEM}

It is important to list the various reports available to the user. In general this applies only to computerised systems since information from manual systems can normally be obtained only either fully or in component chunks like "nursing records" or "clinical notes." Even so, it is worth explaining how the manual record can be broken down.

For computerised systems list the various menus available. A diagram may help to identify the way in which the data are combined into the various options identified in the menus. (The menu is the computer display that allows the user to select what he wants the computer to do-for example, list all names, list all diagnoses, list names by diagnosis, move to next menu, etc.) What the code needs to identify is what is available to the user for each menu option-that is, what reports can be produced. Are all personnel able to obtain access to all menus or all options on each menu? If not, who can gain access to what?

While the preceding comments relate to data, exactly the same applies to software. Not all staff need to manipulate the data using every program available. If there are limitations who can use what software?

All systems have to have procedures for obtaining access to data. In the case of manual systems this will be related to validating authorisations granted by the data custodian or his equivalent. How is this done, and by whom? Can staff obtain manually held data without going through such a system - that is, can the validation be bypassed? If so, how?
For computerised systems, can anyone log in or do they need a password? If they need a password is this issued by the systems administrator or equivalent or are the staff simply allowed to generate their own codes? Are there adequate passwords to protect the security of files that are restricted to certain authorised staff groups? Can they be changed regularly?

For all systems, what level of access is allowed to various grades of staff? Who is allowed to add data? How is this controlled? Are there procedures for adding to or altering manual records? Who monitors this and how? For computerised systems, is the level of access permitted controlled by a separate password or by the individual's $\log$ in password?

On passwords in general, who issues them? If not the systems administrator who and why not the former? Are they properly designed so as to avoid code breaking by association-that is, do they avoid dates of birth, names of children, obvious key words, etc? Are they alphanumeric and random? If not, why not?

\section{OUTLINE OF SECURITY PROCEDURES FOR ELECTRONIC DEVICES}

Where are input devices, processing equipment, and output devices (including visual display units and printers)? How can they be disabled when not in use? Are they in secure rooms? If not, can the rooms be made secure when they are not in use? What measures are taken to ensure that as few people as possible have access to this equipment? Where are hardware and software manuals kept? Are they secure?

\section{RECEIPT, STORAGE, AND OUTPUT OF DATA}

Where do the data come from and how do they get to you? Can they be accidentally diverted to another place or read in error by some unauthorised person? If they are in the form of written material do they have to be transmitted to another part of the building? If so, how is this done? Are sealed envelopes marked "confidential" used? Are locked briefcases used to prevent theft?

Where and how are written data stored? What security measures are available to protect them? Can the storage rooms be locked? For electronic files, what back up systems are available and how are they produced-for example, streamer tapes, disc, or card copies, etc. Where are they kept? How secure are they? Is there a transactional log on the operating system so as to identify the exact point of error in a systems failure?

Who is entitled to request data and how do they do this? Who checks on the identity of people requesting data and how? If the recipient is not an NHS employee what check is there that he is entitled to use the data by virtue of having signed the relevant agreements?

How are data from the computer supplied? How is output protected? Is there a facility for time out when the data accessor is called away to other duties so that the data are withheld from the output device for a specified period of time without the system closing down? How are output data communicated to others? How are they transported? (See receipt of data above.)

\section{UNAUTHORISED RECIPIENTS}

How does the system respond to attempts by unauthorised persons to enter it? Is there a system of logging of unauthorised requests? If computers are used does the terminal misused close down when unauthorised access is sought? If so, how is this effected and what leeway is there for careless or forgetful members of staff to correct errors? What action is taken to follow up attempts to access data by unauthorised personnel? Is there a formal audit trial to identify such personnel?

Visitors are not normally authorised to have access to data but may wish to see the database and the system in operation. Is a dummy file kept for such purposes? If not, how is confidentiality assured in demonstrations of the system? 
If an unauthorised person seeks permission for access to data what are the procedures for considering his request? Such requests could best be dealt with by a district data protection officer, which would take any strain away from staff who are approached-for example, by the police-for release of information. How are requests for information by unauthorised persons monitored? How is subsequent authorisation given, by whom, on what grounds, and how is this monitored and notified to the data custodian and system administrator?

\section{ACCESS BY THE DATA SUBJECT}

How are requests for access by the data subject handled? How are they monitored and effected? If changes to data are requested how are these managed? Are any of the data exempt from data subject access? If so, what? Is it intended to allow data subjects access to these data none the less, and, if so, in what circumstances?

\section{DELETION OF DATA}

How long are data to be kept? Who is to delete them when they are no longer needed? Are they to be transferred to an archive file for later research purposes, and, if so, which?

\section{MANAGEMENT AND DISCIPLINE}

Who is the data custodian and the system administrator? How can the code of practice be updated, altered, or amended? By whom? Who must approve such alteration? Who is entitled to view the code of practice operating for the time being?

What penalties will there be for staff breaking the provisions of the Data Protection Act? What about staff breaching confidentiality with regard to non-identifiable data not covered by that Act? Is there any action to be taken against staff divulging details of the system or its operation? If so, what? Do these provisions relate to employees of other health authorities-for example, the regional health authority? What about people who do not work for the health service but who are concerned in the storage or processing of data? What sanctions are there for them, either by their own employers or by the health authority concerned?

\section{Conclusion}

Dealing with these several points will give any clinician a pretty good idea of how secure his system is. Most will be surprised at how lax their staff are with regard to such important matters-surprised at how such a crucial tool of medical practice as confidentiality can be so subject to carelessness. As Dryden says,

"For secrets are edged tools,

And must be kept from children and fools."

No doctor can afford to jeopardise his practice for the want of good, secure systems of data protection. The time taken to check your system along the lines suggested will be well worth while.

\section{References}

1 Data Protection Act 1984. London: HMSO, 1984

Data Protection Registrar. The Data Protection Act 1984. An introduction and guide to the Act. Guideline No 1. Wilmslow, Cheshire: Data Protection Registrar, 1985.

Steering Group on Health Services Information. A report from the confidentiality working group. London: DHSS, 1984.

4 Department of Health and Social Security. Confidentiality of personal health information. London: DHSS, 1984. (DA (84)25.)

(Accepted 4 September 1985)

\section{Welsh priorities for health}

"The provision of effective and efficient health services in the Principality is one of the main responsibilities of any Secretary of State for Wales," says Nicholas Edwards in the documen Policies and Priorities for Health Services in Wales. "This document provides the basis for a corporate plan for the NHS in Wales." The report states the general policy of this government-tight cash limitation of districts, effective management, cross boundary collaboration with the development of regional and supraregional specialties, which in Wales are controlled by the Welsh Office, the development of community care-especially for the elderly, the mentally ill, and the mentally handicapped-and closer cooperation with the private sector. While setting no detailed objectives -they will come in a report in a few months' time-Mr Edwards does emphasise six priorities within the strategic policies that must be met. These are: to maximise the patient care obtained from the human and financial resources devoted to the National Health Service, to ensure sustained development in continuing care services, to develop health promotion, to complete the present all Wales capital programme, to continue the programme of development in regional services, and to enable district health authorities to develop local services.

Within Wales the progress of these policies and priorities are being watched with interest. Health promotion has received a boost in the establishment of "Heartbeat Wales," a project designed to inform the population about the benefits of exercise, of not smoking, and of a healthy diet in coronary prevention. Local services in some areas are being developed in close cooperation with the private sector. Two districts now have renal dialysis units funded commercially, but using NHS services such as catering and laboratory facilities as well as NHS consultant expertise. After only two months in operation for one of these units it is too early for valid conclusions but so far there have been no serious problems, and the medical staff concerned praise the sensitivity of managers who conducted the delicate negotiations before the unit was established

A great deal of money has been spent in Wales over the past decade on capital projects, not all of which have been completed as originally planned. One of the new district general hospitals-designed in two phases to reduce the number of sites from which the acute services were being provided from four to one-is now unlikely ever to contain all the acute specialties. Instead three sites will remain, and the remaining capital to fund the transfer of one of the major acute specialties to the new site-five years after the first phase openedhas to be found by the district.

The commitment to the expansion of community hospitals - a major part of the text of this document-has been acted on. Many districts have seen the enlargement of existing community hospitals, the conversion of defunct maternity homes or distant parts of the district general hospital, and the building of new community hospitals spread throughout the district and providing an increasing proportion of the care. Before general practitioners become too complacent about their place in the Welsh health services, however, there is a warning that the green paper may alter the Secretary of State's priorities for the family practitioner services.

Policies and Priorities for Health Services in Wales is available from the Welsh Office, Cathays Park, Cardiff.

\section{Selected list successful, according to Secretary of State}

The selected list scheme was running successfully and was on target to save $£ 75$ million a year, the Secretary of State for Social Services claimed in the House of Commons on 12 November. The scheme had, he said, proved to be a sensible way of saving money on the drugs bill and ensured that extra resources went on the health services. Asked why he had allowed the General Medical Services Committee to prevent other doctors from using an appeal mechanism, he replied: "In view of the history of the selected list and the controversy that it aroused in the medical profession it seems rather foolhardy to seek to impose an appeal mechanism on the medical profession, which does not appear to want it." Mr Norman Fowler said that another benefit had been that some drug prices had come down appreciably. 